Shaymaa SH. Hassan BDS, MSc (Asst. Lec.)

\section{An Evaluation of Mechanical Properties of Different Types of Composite Resins (An in Vitro Study)}

Department of Conservative Dentistry

College of Dentistry, University of Mosul

\begin{abstract}
الخحلاصة
الأهداف: تحدف الدراسة المى تقييم الخصائص الميكانيكية (قوة الانضغاط، قوة الشد القطري، قوة الالتواء ومعامل المرونة) لاربعة انواع مختلفة من الكومبوزت. المواد

وطرائق العمل: تم استخدام اثنان من الكومبوزت السيال (tgmicrohybrid, و و اثنان من الكومبوزت التقليدي)

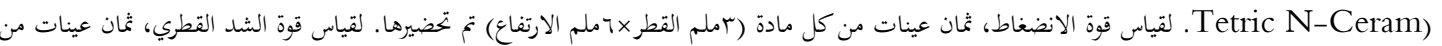

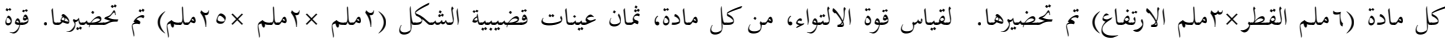

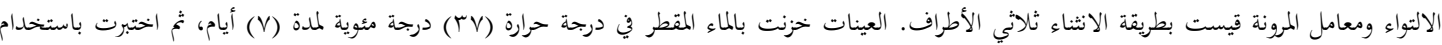
جهاز الاختبار العام بسرعة (املم/الدقيقة) اما اختبار العينات المستقل واختبار دنكن استخدموا للتحليل ألإحصائي. النتائج: قوة الانضغاط، قوة الشد القطري ومعامل المرونة للكومبوزت السيال معنويا اقل من تلك للكومبوزت التقليدي وقوة التواء الكومبوزت السيال (Tetric N-Flow) معنويا اقل من تلك التي للكومبوزت (Tetric N-Ceram) التقليدي، ولكن لا يوجد اختلاف معنوي بين (tgflow) كومبوزت و) كومبوزت في قوة الالتواء. الاستنتاجات: يمكن أن نستنتج بان الخصائص الميكانيكية لنوعين من الكومبوزت السيال أدنى من خصائص النوعين الاخرين من الكومبوزت التقليدي.
\end{abstract}

\begin{abstract}
Aims: The aim of this study was to evaluate the mechanical properties (compressive strength (CS), diametral tensile strength (DTS), flexural strength (FS) and modulus of elasticity (ME)) of different types of composite resins. Materials and Methods: Two flowable composites (tgflow, Tetric N-Flow) and two conventional composites (tgmicrohybrid, Tetric N-Ceram), were used in this study. For CS measurement, eight specimens of each material (3mm diameter x 6mm height) were prepared. For DTS measurement, eight specimens of each material (6mm diamerter x 3mm height) were prepared. For FS measurement, of each material eight bar shaped ( $2 \mathrm{~mm}$ x $2 \mathrm{~mm}$ x $25 \mathrm{~mm}$ ) specimens were prepared. The FS and ME were determined by three point bending method. The specimens were stored in distilled water at $37^{\circ} \mathrm{C}$ for 7 days, then tested on a universal testing machine at a crosshead speed of $1 \mathrm{~mm} / \mathrm{mint}$. Independent sample t-test and Duncan test were used for statistical analysis. Results: The CS, DTS and ME of flowable composites were significantly lower than that of the conventional composites, the FS of flowable (Tetric N-Flow) composite was significantly lower than that of the conventional (Tetric $\mathrm{N}$-Ceram) composites but there was no significant difference between tgmicrohybrid composite and tgflow composite in FS. Conclusions: It can be concluded that the mechanical properties of two flowable types composites were inferior than that of the two conventional types composites.
\end{abstract}

Keywords: Mechanical properties, Flowable composite, Flexural Strength

Hassan SH SH. An Evaluation of Mechanical Properties of Different Types of Composite Resins (An in vitro study). Al-Rafidain Dent J. 2014; 14(1):123-131.

\section{INTRODUCTION}

In restorative dentistry, choosing the correct restorative material is one of the primary variables that determine its success. However, it is impossible to refer to an ideal material in regard to dental restoration. In order to lessen a material's negative effects, dentists must know its mechanical, chemical, biological and clinical properties well. ${ }^{(1)}$ The mechanical properties of light cured composite resins are a crucial factor for their clinical performance. These properties are tightly related to the material composition (organic matrix and inorganic filler). ${ }^{(2)}$

Flowable composites are low viscosity resin based restorative materials that differ from conventional resin composites in their filler load and resin content. Flowable contains the same filler particles as traditional hybrid composites, but contains 20-25\% less filler than 
conventional materials. $^{(3)}$ In general, variation in the filler content heavily affects mechanical strength. Therefore, in order to obtain greater fluidity for flowable composites it must be done at the expense of certain properties. ${ }^{(4)}$ Flowable composites are being used for a wide range of applications, from liners and pit and fissure sealents, to margin or void repairs and even Class I, III, and V restorations. Because flowable composites are being used in many clinical applications, dentist need comparative information so that they can select the materials with most appropriate properties for any particular use. ${ }^{(5)}$

Compressive strength is defined as the compressive stress within compression at the point of fracture, it is an important property in the process of mastication because many of the forces of mastication are compressive in nature. ${ }^{(6)}$ Diametral tensile strength testing was developed to investigate brittle materials with little or no plastic deformation. In this test, cylindrical specimen is submitted to a compressive load in the diametral plan, which is perpendicular to the longitudinal axis. In both types of testing, specimens are submitted to a compressive load applied at different planes and fracture occur as a result of tensile and complex shear stresses within the material. ${ }^{(7)}$

The flexural strength is, in a sence, a collective measurement of tensile, compressive and shear stresses simultaneously. ${ }^{(8)}$ Flexural strength test employs rectangular bar specimens submitted to three or four point bending, producing tensile stresses on the lower surface of the specimens and compressive stresses on the upper surfaces where load is applied. ${ }^{(7)}$

The modulus of elasticity is the relative stiffness of a material. A material having a higher elastic modulus is more rigid, conversely, a material with a lower modulus is more flexible. ${ }^{(9)}$ Different clinical situations demand resin-based restorative materials with different moduli of elasticity. Class V (cervical) cavities, for example, demand a low modulus restorative material to flex with the tooth. A relatively high modulus, on the other hand, is expected from posterior composites to withstand the occlusal forces and preserve the adhesive interface. ${ }^{(10)}$

The purpose of this study was to determine the compressive strength, diametral tensile strength, flexural strength, and modulus of elasticity of different types of composite resins.

\section{MATERIALS AND METHODS}

Four composite resins of A2 shade were used in this study; two flowable composites (tgflow (TGF) (Technical and General Ltd, United Kingdom); and Tetric N-Flow (TNF) (Ivoclar vivadent, Liechtenstein) and two conventional composites (tgmicrohybrid (TGM) and Tetric-NCeram (TNC)) from the same manufactures as controls (Figure 1). Eight samples of each material were made for each test.

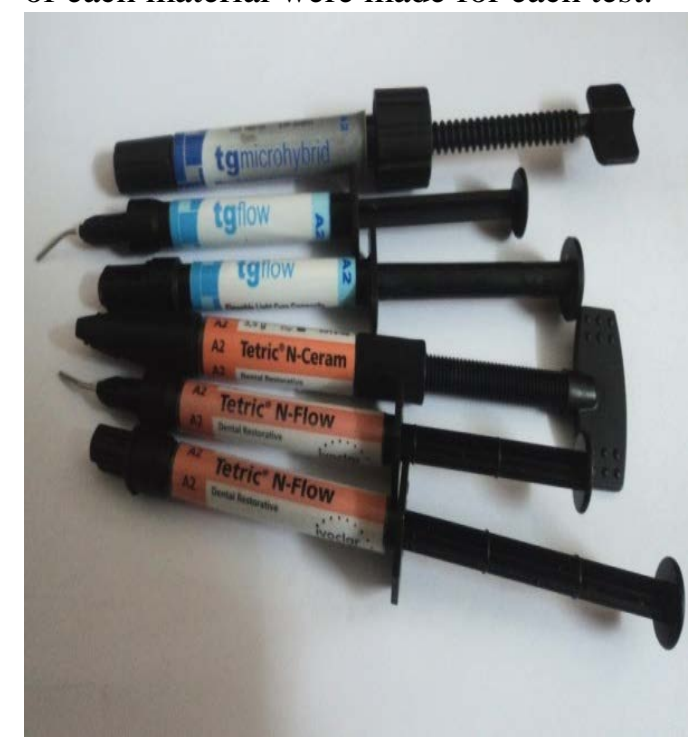

Figure (1): Composite resins used in the study.

Compressive strength test:

For compressive strength (CS) measurement, the specimens were prepared in cylindrical teflon mold with an inner diameter of $3 \mathrm{~mm}$ and a height of $6 \mathrm{~mm} .{ }^{(1,11,12,13,14)}$ The mold was placed on a glass slab. The composite resins were placed in increments of approximately $2 \mathrm{~mm}$, the last increment was covered with a polyster strip and pressed with microscopic slide to expel excess material from the mold. Each increment was cured for 40 sec. using QTH light curing unit (Astralis, VIVADENT, Austria), the light intensity $\left(450 \mathrm{~mW} / \mathrm{cm}^{2}\right)$ was checked every five exposures using a radiometer (Cromatest 7041, Megaphysik, Germany). 
The cured samples were stored in distilled water, at $37^{\circ} \mathrm{C}$ in an incubator for one week. ${ }^{(12,15)}$ After storage, the CS was measured using a computerized universal testing machine (Alfa, UK) at a crosshead speed of $1 \mathrm{~mm} / \mathrm{mint}$. The specimens were positioned vertically on the testing ma-

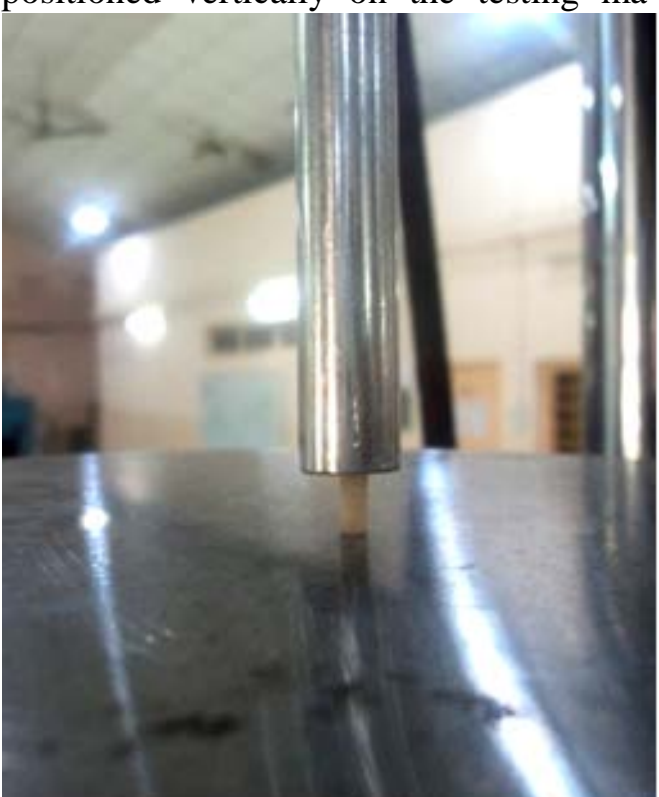

Figure (2): Specimen subject to compressive load

Diametral tensile strength test

For diametral tensile strength (DTS) measurement, the composite resins were chine base and subjected to compressive load until failure (Figure 2,3). CS was calculated in MPa by dividing failure load (F) in Newton $(\mathrm{N})$ by the cross sectional area, $\mathrm{CS}=\mathrm{F} / \pi \mathrm{r}^{2}, \mathrm{r}$ is the radius of cross-section of the specimen, $\pi=3.14$.

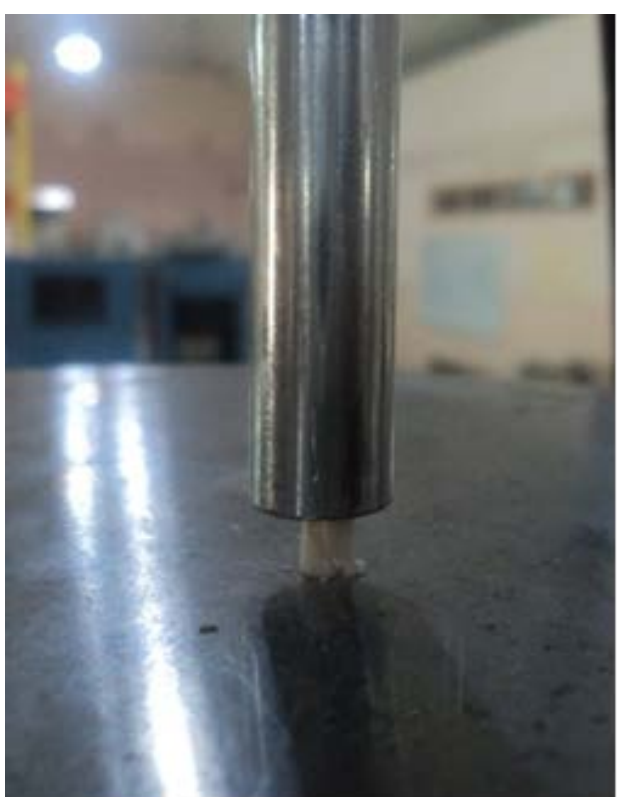

Figure (3): Specimen failure under compressive load

placed in cylindrical teflon mold with $6 \mathrm{~mm}$ diameter and $3 \mathrm{~mm}$ height. ${ }^{(1,11,13)}$ (Figure 4).

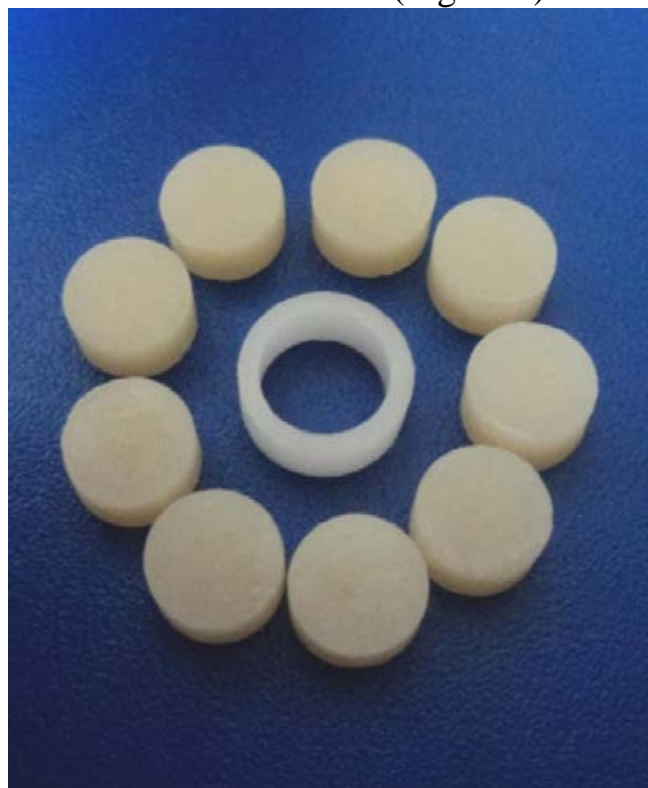

Figure (4): Mold and specimens for DTS test

The mold was placed on a glass slab. The composite resins were packed into the mold, covered with a polyester strip and pressed with microscopic slide to expel excess material from the mold then light cured for $40 \mathrm{sec}$. from the top and bottom of the mold with QTH light curing unit. The cured samples were stored in distilled 
water, at $37^{\circ} \mathrm{C}$ in an incubator for one week. After storage, the DTS was measured using universal testing machine at a crosshead speed of $1 \mathrm{~mm} / \mathrm{mint}$. The specimens were placed on their sides and the load was applied vertically on the lateral portion of the cylinder until failure (Figure 5). DTS was calculated in MPa using the following equation: $\mathrm{DTS}=2 \mathrm{~F} / \pi \mathrm{DH}$ where $\mathrm{F}$ is the failure load (in N), D is the diameter of the specimen, $\mathrm{H}$ is the height of the specimens.

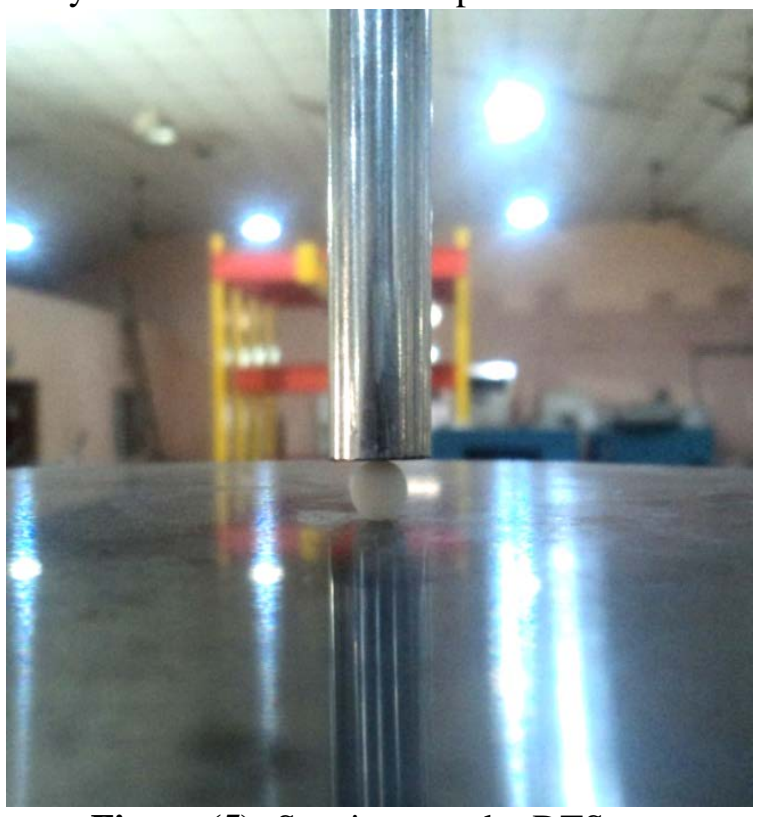

Figure (5): Specimen under DTS test

Flexural strength test

Flexural strength (FS) was evaluated according to ISO 4049 specification ${ }^{(16)}$, a three point bending method. The compo- site resins were placed into rectangular split glass mold, $25 \mathrm{~mm}$ in length, $2 \mathrm{~mm}$ in width and $2 \mathrm{~mm}$ in height (Figure 6).

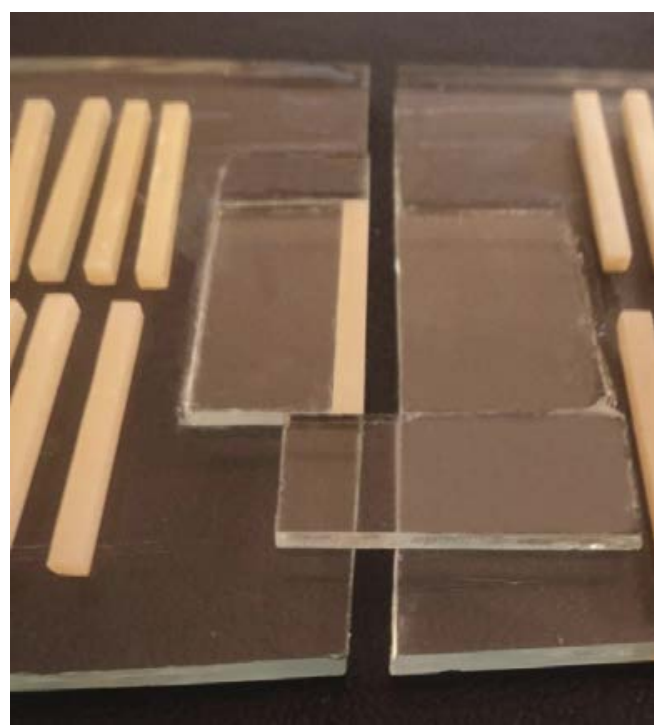

Figure (6): Split glass mold and specimens for FS test.

The composite resins were placed in the mold in a one increment covered with a polyester strip and pressed with a microscopic glass slide for excess removal. Each specimen was cured for $40 \mathrm{sec}$. with QTH light curing unit in four overlapping positions of 40 sec each, across the length of the mold. The cured samples were stored in distilled water, at $37^{\circ} \mathrm{C}$ in an incubator for one week. After storage the flexural strength was measured using universal testing machine at a crosshead 
speed of $1 \mathrm{~mm} / \mathrm{mint}$. Each specimen was loaded at its center until the specimen was fractured (Figure 7). Flexural strength was calculated in $\mathrm{MPa}$ using the following equation: $\mathrm{FS}=3 \mathrm{FL} / 2 \mathrm{BH}^{2}$, where $\mathrm{F}$ is the maximum load (in $\mathrm{N}$ ), $\mathrm{L}$ is the distance between the supports $(20 \mathrm{~mm}), \mathrm{B}$ is the width of the specimen $(2 \mathrm{~mm}), \mathrm{H}$ is the height of the specimens $(2 \mathrm{~mm})$.

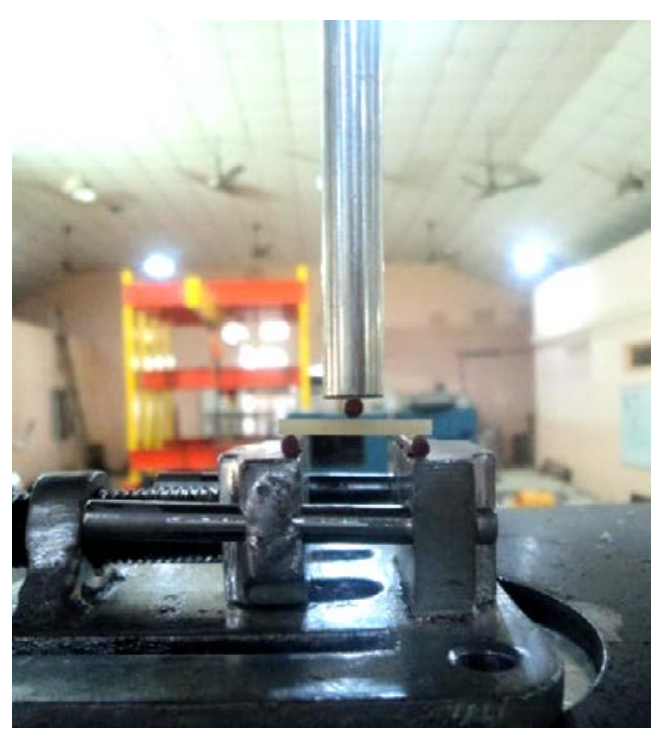

Figure (7): Specimen loaded at its center according to three points bending method.

Modulus of elasticity test

Modulus of elasticity (ME) was calculated in $(\mathrm{GPa})$ from three points bending test using the following equation ${ }^{(10,17)}$ : $\mathrm{ME}=\mathrm{FL}^{3} / 4 \mathrm{BH}^{3} \mathrm{~d}$, where $\mathrm{F}$ is the maximum load $(\mathrm{N}), \mathrm{L}$ is the distance between the supports $(20 \mathrm{~mm}), \mathrm{B}$ is the width of the specimen $(2 \mathrm{~mm}), \mathrm{H}$ is the height of the specimens $(2 \mathrm{~mm})$, and $\mathrm{d}$ is the deflection in millimeters corresponding to load $\mathrm{F}$ (Figure 8).

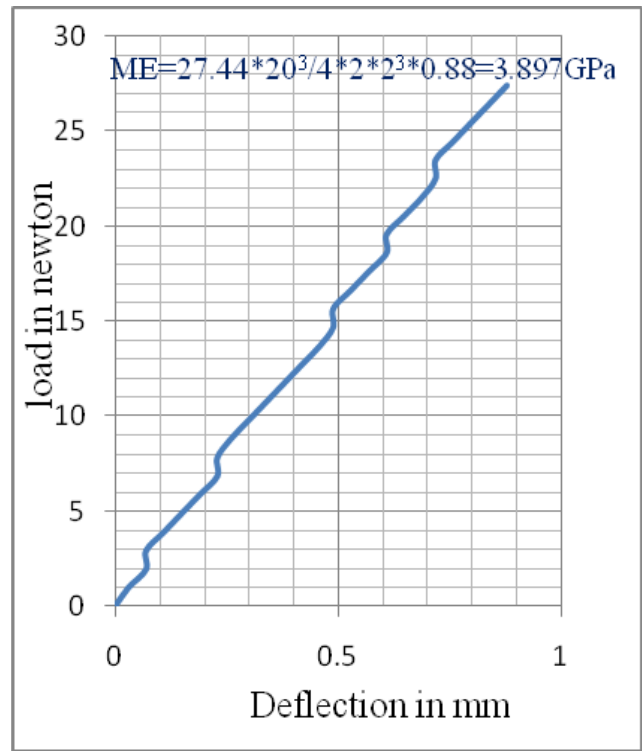

Figure (8): Load versus deflection of conventional types of composite

\section{RESULTS}

Descriptive statistics of all mechanical tests for all materials are shown in Table (1). Independent sample t-test (Table 1) was conducted on all mechanical test results to compare the difference between flowable composites and conventional composites. Duncan test (Table 2 to 5) was utilized to compare the differences among groups of materials. All statistical analysis were considered significant at $p \leq 0.05$. 
T-test, (Table 1) showed that the CS of Flowable composites was significantly lower than the CS of the conventional composites. T-test (Table 1) showed that the DTS of Flowable composites was significantly lower than the DTS of the conventional composites. T-test (Table 1) showed that the FS of TNF was signifi- cantly lower than the FS of the TNC, while there was no significant difference between TGF and TGM in FS. T-test (Table 1) showed that the ME of Flowable composites was significantly lower than the ME of the conventional composites.

Table (1): Descriptive statistic and Independent sample t-test for the mechanical strength tests of the tested materials.

\begin{tabular}{lllllllll}
\hline $\begin{array}{l}\text { Mechanical } \\
\text { test }\end{array}$ & $\begin{array}{l}\text { Tested } \\
\text { Material }\end{array}$ & \multicolumn{9}{c}{ Descriptive Statistic } & & $\begin{array}{c}\text { Independent Samples } \\
\text { t-Test }\end{array}$ \\
\cline { 3 - 9 } & & N & Mean & $\begin{array}{l}\text { Standard } \\
\text { Deviation }\end{array}$ & $\begin{array}{l}\text { Minimum } \\
\text { value }\end{array}$ & $\begin{array}{l}\text { Maximum } \\
\text { value }\end{array}$ & t & P-value \\
\hline CS & TNC & 8 & 237.43750 & 8.815264 & 227.883 & 254.777 & 11.274 & 0.000003 \\
(MPa) & TNF & 8 & 182.94350 & 10.449296 & 161.358 & 193.913 & & \\
& TGM & 8 & 231.95263 & 9.760582 & 209.483 & 239.207 & 10.680 & 0.000001 \\
& TGF & 8 & 170.20463 & 13.120653 & 147.204 & 181.174 & & \\
DTS & TNC & 8 & 48.61050 & 1.282122 & 47.062 & 50.955 & 13.088 & 0.0002 \\
(MPa) & TNF & 8 & 36.79813 & 2.207505 & 33.260 & 40.339 & & \\
& TGM & 8 & 52.10500 & 1.162158 & 50.955 & 54.140 & 13.312 & 0.00011 \\
& TGF & 8 & 41.66625 & 1.889000 & 39.278 & 43.878 & & \\
FS & TNC & 8 & 106.18200 & 5.305286 & 99.225 & 113.557 & 3.343 & 0.005 \\
(MPa) & TNF & 8 & 97.84438 & 4.649256 & 91.875 & 103.800 & & \\
& TGM & 8 & 98.58150 & 3.927549 & 92.977 & 104.553 & 1.199 & 0.250 \\
& TGF & 8 & 95.64163 & 5.712789 & 89.302 & 103.267 & & \\
ME & TNC & 8 & 4.39537 & 0.073015 & 4.287 & 4.506 & 41.387 & 0.00011 \\
(GPa) & TNF & 8 & 3.05050 & 0.055824 & 2.979 & 3.110 & & \\
& TGM & 8 & 5.44400 & 0.217624 & 4.971 & 5.641 & 17.649 & 0.0002 \\
& TGF & 8 & 3.94363 & 0.102257 & 3.835 & 4.134 & & \\
\hline
\end{tabular}

Table (2) showed that there was no significant difference between TNC and TGM in CS. Table (3) showed that the
DTS of TGM were significantly higher than the DTS of TNC.

Table( 2): Duncan test for Compressive strength test

\begin{tabular}{lllll}
\hline Tested Materials & TNC & TNF & TGM & TGF \\
\hline Duncan Grouping & C & B & C & A \\
\hline
\end{tabular}

Table (3): Duncan test for Diametral tensile strength test

\begin{tabular}{lllll}
\hline Tested Materials & TNC & TNF & TGM & TGF \\
\hline Duncan Grouping & C & A & D & B \\
\hline
\end{tabular}

Table (4) showed that FS of TNC was significantly higher than the FS of TGM. Table (5) showed that the ME of TGM were significantly higher than the ME of TNC. 
Table (4): Duncan test for Flexural strength test

\begin{tabular}{lllll}
\hline Tested Materials & TNC & TNF & TGM & TGF \\
\hline Duncan Grouping & B & A & A & A \\
\hline
\end{tabular}

Table (5): Duncan test for Modulus of elasticity test

\begin{tabular}{lllll}
\hline Tested Materials & TNC & TNF & TGM & TGF \\
\hline Duncan Grouping & C & A & D & B \\
\hline
\end{tabular}

Note: Different letters mean significant differences

\section{DISCUSSION}

Recently, flowable composites are widely used in clinical practice instead of conventional composites which are hybrid filled composites with high consistency. ${ }^{(4)}$ The filler content, size, type, and distribution, as well as coupling between particles and matrix are factors that influence mechanical properties such as strength and modulus of elasticity. ${ }^{(13)}$

The test of CS revealed that the flowable composites exhibited lower CS than conventional composites, this can be explained by the lower filler content of flowable composites. The higher filler content probably strengthens the matrix so as to enable the material to withstand high compressive stresses. $^{(17)}$ Mota et al., $2011^{(14)}$, showed that the amount of filler weight directly increased the CS. This result agree with Miyasaka and Okamura $2009^{(4)}$ showed that the CS of conventional composites was higher than that of flowable composites and the mechanical strength tended to increase with increase in filler content. Table 2 showed that there was no significant difference between TNC and TGM in CS.

DTS is an acceptable and common test for dental composite, DTS values of the composites tested in the present study are in the DTS range of dental composite 30$55 \mathrm{Mpa}^{(18)}$

The result of the test for DTS revealed that the DTS of flowable composites were significantly lower than conventional composites. This result could be attributed to the lower filler content of flowable composites than conventional composites. Zandinejad et al., (2006) ${ }^{(18)}$ reported that an increase in filler content in matrix improve the mechanical properties of dental composite, such as compressive and diametral tensile strengths. Lu et al., 2006 $6^{(19)}$ showed that the composite with lower fill- er loadings had lower DTS. Table (3) showed that TGM composite had the higher DTS value than TNC with significant difference, this may be explained by volumetric content of the inorganic filler, TGM has $64 \%$ by volum of inorganic filler content, while TNC has $57 \%$ by volum of inorganic filler content. Another factor that can explain such result is the organic phase composition. The monomer composition of TGM is Bis-GMA, UDMA and TEGDMA, while TNC is Bis-GMA and BISEMA, without TEGDMA which is flexible low viscosity monomer. The DTS was found to depend on the degree of conversion of methacrylate double bonds. ${ }^{(20)}$ It is well known that the degree of conversion of methacrylate monomer depends on the nature of the polymerizing monomers in such a manner that more flexible monomer molecules give rise to increased degree of conversion. ${ }^{(21)}$ Asmussen et al., $1998^{(15)}$ and Bona et al., $2008^{(22)}$ have been reported that replacing Bis-GMA by TEGDMA increase the DTS, whereas replacing either Bis-GMA or TEGDMA by UEDMA increase the DTS.

The experiment for FS revealed, TNC had higher FS than TNF with significant difference, this can be explained by higher volume of filler content of TNC which improve its intrinsic properties $(57 \%$ by volume for TNC and 39\% by volume for TNF), this result agreed with Lee et al., $2006^{(23)}$ concluded that the FS of flowable composites was significantly lower than that of restorative composites due to the filler content of the composite resins. Another cause may be due to presence of TEGDMA in the matrix of TNF which decrease the FS. The presence of TEGDMA in the composite matrix composition has been associated to a significant decrease in the FS of the material. ${ }^{(15)}$ However, there was no statistical difference 
between TGM and TGF in FS test. The minimum three point FS value for light cured direct restorative materials is 80 $\mathrm{MPa}^{(16)}$, all the composites investigated in this study showed higher FS values than the ones recommended by the ISO. Table (4) showed that FS value of TNC significantly higher than TGM. This result may be due to filler size difference between two materials, TNC is nanohybrid composite, the filler size is $(40 \mathrm{~nm}-3000 \mathrm{~nm})$, while TGM is microhybrid composite, the average filler size is below $1 \mu \mathrm{m}$. Following increasing filler particle size an increase in stress concentration and decrease in FS is observed. (24) Table (1) showed that ME of flowable composites was significantly lower than that of conventional composites. Again this may be attributed to lower filler content of flowable composite than conventional composites. It has been reported a significant correlation between ME and percentage of filler. ${ }^{(25)}$ This result agree with Xavier et al., (2010) ${ }^{(26)}$ showed that the conventional resin presented significantly higher ME than flowable resins. Table (5) showed that ME of TGM was significantly higher than that of TNC, this result may be due to presence of TEGDMA in matrix composition of TGM composite. The presence of TEGDMA in the matrix composition has been associated to an increase in modulus of elasticity. ${ }^{(15)}$ The characteristic flexibility of TEGDMA allows the creation of a dense and flexible polymer network that increases the composite elastic deformation. ${ }^{(10)}$

\section{CONCLUSION}

The two flowable types composites had lower mechanical strength than the two conventional types composites, and they should be not used in areas that experience high occlusal loading.

\section{REFERENCES}

1. Siso SH, Hurmuzlu F. Physical properties of three different types of light cured composite resins. Acta Stomatol Croat. 2008; 42(2):147-154.

2. Manolea H, Degeratu S, Deva V, Coles E and Draghici E. Contributions on the study of the compressive strength of the light cured composite resins. Current Health Sciences J. 2009; 35(1):62-65.

3. Cadenaro M, Marchesi G, Antoniolli F, Davdson C, Dorigo EDS and Breschi L. Flowability of composites is no guarantee for contraction stress reduction. Dent Mater. 2009; 25(5):649-654.

4. Miyasaka T and Okamura H. Dimentional change measurements of conventional and flowable composite resins using laser displacement sensor. Dent Mater J. 2009;28(5):544551.

5. Attar N, Tam LE, McComb D. Flow, strength, stiffness and radiopacity of flowable resin composites. $J$ Can Dent Assoc.2003; 69(8): 516-521.

6. Cobb DS, MacGregor KM, Vargas MA, Denehy GE. The physical properties of packable and conventional posterior resin based composites.JADA.2000;131:1610-1615.

7. Anusavice KJ. Phillips: science of dental materials. $11^{\text {th }}$ ed. St. Louis:W B Saunders; 2003.

8. Tjandrawinata $\mathrm{R}$, Irie $\mathrm{M}$ and Suzuki K. Flexural properties of eight flowable light cured restorative materials in immediate vs. 24-hour water storage. Oper Dent. 2005; 30(2):339-249.

9. Papadogiannis Y, Lakes RS, Palaghias G, Antoniades MH, Papadogiannis D. Fatigue of packable dental composites. Dent Mater. 2007; 23(2):235-242.

10. Junior SAR, Zanchi $\mathrm{CH}$, Carvalho RV, Demarco FF. Flexural strength and modulus of elasticity of different types of resin based composites. Barz oral res. 2007;21(1):16-21.

11. Urabe H, Nomura Y, Shiral K, Yoshioka M, Shintani H. Effect of filler content and size to properties of composite resins on microwave curing. J Mater Science: Materials in Medicine.1999;10:375-378.

12. Razooki Al-Shekhli AA. In-home bleaching effect on compressive strength values of some direct resto ative materials. J International Dental And Medical Research. 2010; 3(1):15-18.

13. Obici AC, Sinhoret MAC, CorrerSobrinho L, Goes MF, Consani S. 
Evaluation of mechanical properties of Z250 composite resin light cured by different methods. J Appl Oral Sci. 2005;13(4):393-398.

14. Mota EG, Weiss A, Spohr AM, Oshima HMS, Carvalho LMN. Relationship between filler content and selected mechanical properties of six microhybrid composites. Rev odonto ciệnc. 2011; 26(2):1-9.

15. Asmussen $\mathrm{E}$ and Peutzfeldt A. Influence of UEDMA, Bis-GMA and TEGDMA on selected mechanical properties of experimental resin composites. Dent Mater.1998;14:51-56.

16. International Standard ISO 4049. Polymer based filling restorative and luting materials. Technical Committee 106-Dentistry. International Standards Organization Geneva, Switzerland, Fourth edition, 2009.

17. Kilaru KR. Comparative evaluation of compressive strength, vickers hardness and modulus of elasticity of hybrid and packable (condensable) posterior composites: An in vitro study. M.Sc thesis, S.D.M College of dental sciences and hospital, Dharwad. Rajiv Gandhi University of Health Sciences, Bangalore (2006).

18. Zandinejad AA, Atai M, Pahlevan A. The effect of ceramic and porous fillers on the mechanical properties of experimental dental composites. Dent Mater. 2006;22(4):382-387.

19. Lu H, Lee YK, Oguri M, Powers JM. Properties of a dental resin com- posite with a spherical inorganic filler. Oper Dent.2006;31(6):734-740.

20. Asmussen E. Restorative resins: hardness and strength vs. quantity of remaining double bonds. Scand $J$ Dent Res.1982; 90:484-489.

21. Ruyter IE and Øysaed H. Composites for use in posterior teeth: composition and conversion. $J$ Biomed Mater Res.1987;21:11-23.

22. Bona AD, Benetti P, Borba M, Cecchetti D. Flexural and diametral tensile strength of composite resins. Braz Oral Res.2008;22(1).

23. Lee SH, Pae A, Kim SH. A comparative study between degree of conversion and flexural strength of composite resins. J Korean Acad Prosthodont. 2006; 44(3): 333-342.

24. Tanimoto $\mathrm{Y}$, Kitagawa T, Aida M, Nishiyama N. Experimental and computational approach for evaluating the mechanical characteristics of dental composite resins with various filler sizes. Acta Biomater. 2006; 2(6):633-639.

25. Ikejima I, Nomoto R, McCabe JF. Shear punch strength and flexural strength of model composites with varying filler volume fraction, particle size and silanation. Dent $M a-$ ter.2003;19(3):206-211.

26. Xavier et al. Polymerization shrinkage and flexural modulus of flowable dental composites. Mat Res. 2010; 13(3):380-384. 